\title{
Investigation on the awareness of hepatitis B virus among health care workers in Nigeria
}

\author{
Ekpenyong $\mathrm{MS}^{1 *}$, Tawari-Ikeh $\mathrm{EP}^{2}$ and Ekpenyong $\mathrm{AS}^{3}$ \\ ${ }^{1}$ Faculty of Education, Health and wellbeing, University of Wolverhampton, United Kingdom \\ ${ }^{2}$ Department of Chemical Pathology, College of Health Science, Niger Delta University, Nigeria \\ ${ }^{3}$ Department of Sociology, Faculty of Social Science, Niger Delta University, Bayelsa State, Nigeria
}

\begin{abstract}
Hepatitis B is a disease caused by the hepatitis B virus (HBV), which is transmitted through percutaneous or mucosal exposure to infective blood or body fluids. It is a major problem because it can cause chronic infection, resulting in cirrhosis of the liver, liver cancer, liver failure, and even death The main aim of the study was to investigate the Awareness of hepatitis B virus among health care workers at the Federal Medical Centre Asaba, Nigeria; to assess the attitude of health care workers' vaccination against HBV; and to assess the barrier to predictors for effective hepatitis B virus among health care workers. Two-hundred and fifteen copies of questionnaire were distributed and 161 copies were retrieved, which shown overall response rate of 74.9\%. The data was analyzed using SPSS and cross-tabulation, percentage and chi-square utilized. The results revealed that health care workers have poor knowledge of hepatitis B virus; the use of protective material appeared to be influenced by the perceived risk of transmission and majority indicating that overall practices towards hepatitis B virus (HBV) prevention was good. Based on the finding, the study recommends that; there is a need to inform heath care workers (HCN) of the availability of an effecting, safe vaccine that prevent $\mathrm{HBV}$. All health care facilities should have programs designed to minimize risk, including infection control programs; hepatitis B vaccine protocol should be available at each health care facility; and programs need to be implemented to identify HBV positive HCNs and transfer them for appropriate medical management for vaccination.
\end{abstract}

\section{Introduction}

Hepatitis B virus (HBV) infection is a major global health problem [1,2], especially in Asia, Africa, Southern Europe and Latin America [3]. About 2 billion people are infected with $\mathrm{HBV}$ worldwide [3], and 400 million among them are suffering from chronic HBV infection [4]. The reason may be the lack of proper health facilities; poor economic status and less public awareness about the transmission of major communicable awareness diseases. The major route of HBV transmission in sub-Saharan Africa is horizontal (that is transmission unrelated to recognize-sexual, perinatal, parenteral exposure) [5] in children under 5 years of age; however, percutaneous/parenteral transmission is also an important mode of spread [6].

Health Care Workers (HCWS) may be exposed to the risk of infection with blood-borne viruses (BBVS) such as $\mathrm{HBV}$, hepatitis $\mathrm{C}$ virus (HCV and human immunodeficiency virus HIV) via contract with blood (and other body fluids) in the course of their work [7]. The form of exposure most likely to result in occupational BBV infection is needle stick injury (NSI). A safe and effective vaccine against HBV is available throughout world, yet many health care workers in resourcepoor countries remain at risk because they are not vaccinated against hepatitis B virus [8].

The main aims of this study is to investigate the effect of HBV among health care workers in five (5) Asaba metropolis. The specific objectives are to assess the level of knowledge of health care workers about vaccination against $\mathrm{HBV}$; to assess the attitude of health care workers' vaccination against $\mathrm{HBV}$ and to assess the barriers to predictors for effective hepatitis B virus vaccination among health care workers at Federal Medical Centre (FMC) Asaba.
The following research questions were addressed in this study. Firstly, does the level of Knowledge about hepatitis B influence health care workers to vaccinate against HBV? Secondly, what attitudes do health care workers in Asaba have towards hepatitis B vaccination? Thirdly, to what extent is the proportion of health care workers in Asaba vaccinated against HBV? And lastly, what are the barriers to predictors for effective $\mathrm{HBV}$ vaccination among health care workers at FMC Asaba?

\section{Methodology}

In pursuance of the objective of the study, attentions were focused on a survey on public awareness of Hepatitis B among health care workers in Federal Medical Centre, Asaba. Descriptive study conducted in Federal Medical Centre in Asaba metropolis. Randomly sampling was used for this study. The study followed a quantitative approach, and participants completed a self-administered questionnaire to access their knowledge, attitude and practice (KAP) regarding HBV.

\section{Population and sample size}

The population of this study included all qualified doctors and nurses working at Federal Medical Centre, Asaba who consented to

Correspondence to: Ekpenyong MS, Faculty of Education, Health and wellbeing, University of Wolverhampton, United Kingdom, E-mail: M.s.Ekpenyong@wlv.ac.uk

Key words: knowledge, attitude, practice hepatitis b virus, health care workers, Nigeria

Received: September 22, 2016; Accepted: October 24, 2016; Published: October 28,2016 
take part in this study were included.

The sample size for the study was calculated at $80 \%$ power and a $95 \%$ confidence level at 146 . This was based on the following assumption (a) at least $21 \%$ of HCWs will be vaccinated, (b) $40 \%$ of those who have good knowledge about HBV vaccination are vaccinated against $\mathrm{HBV}$, and (c) $70 \%$ of those who have poor knowledge of $\mathrm{HBV}$ vaccination are vaccinated against HBV [9]. One hundred and sixty-one (161) randomly selected nurses and doctors from Federal Medical Centre, Asaba who consented to participate were given questionnaires.

\section{Data collection tool}

Data was collected through a questionnaire which was formulated by the researchers and divided into 4 sections.

1. Demographics: Comprised of respondents' age, gender, job category, duration as health care worker (years) and health care site.

2. Knowledge test: Since the study population was HCWs, respondents were expected to know that one can get hepatitis B through a needle stick injury; there is an effective vaccine for hepatitis $B$; after vaccination for hepatitis $B$, a blood test is needed to confirm immunity against hepatitis B; the hepatitis B vaccine provide $100 \%$ protection for $90 \%$ of adults and children; the hepatitis B vaccine protects against $\mathrm{HBV}$ for at least 15 years; patients who are vaccinated against hepatitis $\mathrm{B}$ can still be considered as a possible source of hepatitis $\mathrm{B}$; a person who has been vaccinated or recovered from a previous hepatitis B infection, can still infect others. Statements were phrased either correctly or incorrectly, and respondents had to choose one option between "true", "false", don't know".

3. Practice test: This was concerned with exposure to and or protection against hepatitis B virus. Information concerning vaccination, such as have you been vaccinated against hepatitis B virus?, if vaccinated, how many doses?, was your immunity against hepatitis B checked after vaccination?, how many times during your working lifetime have you experienced a needle stick or sharp injury involving a needle or sharp instrument that had been used on a patient?, how many times in the last year have you experienced blood or body fluids splashing in your eyes or mouth?, and do you wear protective clothing when handling blood or body fluids?

The analysis identified the level of practice of HCWs about vaccination against HBV. Respondents had to choose one of the options, namely, for vaccination: 1 dose, 2 doses or 3 doses; for immunity; checked and not checked; protected and not protected; for universal precautions: always, sometimes, never and don't know.

4. Attitude test: Questions consisted of: hepatitis B vaccination should be compulsory for HCWs; hepatitis B vaccination is too expensive; I am scared of being vaccinated because it hurts; I am not at risk for hepatitis B because I am always careful when examining patients and taking specimens; careful when examining patients and taking specimens; I am not at risk for HBV because I am a healthy person; I don't trust vaccinations; and vaccination is against my religion, or traditional beliefs. From these questions respondents had to choose one of the options: strongly agree, agree, don't know, disagree and strongly disagree.

\section{Reliability and validity of the study}

The questionnaire was pretested to 10 Health care workers from an institution which was not randomly selected. This was done to check on the validity if the question that is to see if the questions were clear and gave valid information. The questionnaires were formulated in such a way that the measure accounts for all the elements of the variables, which are knowledge, attitudes and practices. This ensured content validity. Threats to external validity were prevented as random selection of health care workers was done during sampling. Health care workers were sampled from difficult health care settings. Simple random selection also allowed one to draw externally valid conclusions about the entire population based on the sample.

\section{Bias}

Errors introduced by bias were minimized by making the study sample statistically powerful (that is at $80 \%$ and $95 \%$ confidence), and then increasing the sample size further. Also the sample was randomly selected, to make the sample as representatives of the population as possible. The steps minimized errors due to the following:

1. Recall Bias: This could have resulted when those who had previously been occupationally exposed to HBV (for example through a NSI) recalled facts about $\mathrm{HBV}$ and $\mathrm{HBV}$ vaccination better than those who had never been exposed.

2. Volunteer Bias: A poor response rate results in volunteer bias, since volunteers may have different health behaviours than people who refuse to participate. Volunteer bias is unavoidable, since people cannot be forced to take part in a study. However, it was minimized by increasing the sample size to allow for non-response, and a statistically powerful sample size was reached.

\section{Data analysis techniques}

Analytical tools such as percentage and mean were employed in this study. Statistical Package for Social Sciences (SPSS) was utilized in the analysis of the data.

\section{Results}

Two hundred and fifteen questionnaires are distributed as described, and one hundred and sixty-one were returned, giving an overall responses rate of $74.9 \%$. All the respondents were from public hospital.

\section{Background characteristic}

The background profile of the respondents (Table 1) indicated that majority of the respondents were female, $(70.8 \%$ [114/16]) and Nurse predominated $(56.5 \%[91 / 161])$. It also indicated that the majority of the respondents $(57.1 \%$ [92/161]) had been employed as Health Care Workers for more than ten years.

\section{Knowledge about vaccination against hepatitis $B$}

The first research objective in this study was to identify the level of

Table 1. Background profile of respondents.

\begin{tabular}{|c|c|c|c|c|}
\hline $\mathbf{S} / \mathbf{N}$ & Item Statement & Respondent & Frequency & Percentage \\
\hline \multirow[t]{2}{*}{1} & \multirow[t]{2}{*}{ Gender } & Male & 46 & \\
\hline & & Female & 114 & 70.8 \\
\hline \multirow[t]{2}{*}{2} & \multirow[t]{2}{*}{ Job Category } & Doctor & 69 & \\
\hline & & Nurse & 91 & \\
\hline \multirow[t]{6}{*}{3} & \multirow{6}{*}{$\begin{array}{l}\text { Duration as Health Care } \\
\text { worker }\end{array}$} & 5 years or less & 44 & \\
\hline & & $6-10$ years & 24 & \\
\hline & & $11-15$ years & 23 & \\
\hline & & $16-20$ years & 25 & \\
\hline & & More than 20 years & 44 & \\
\hline & & No answer & 1 & \\
\hline
\end{tabular}


knowledge of Health Care Workers about vaccination against HBV. Nine items measured the number of correct responses on general knowledge questions regarding vaccination against $\mathrm{HBV}$. The potential range of scores was 0-9. Poor knowledge was defined as scores of 3 or less, moderate knowledge as 4 to 6 , and good knowledge as 7 to 9 . The actual scores ranged from 0 to 8 with a mean score of $3.13(\mathrm{SD}=1.47)$. Overall, $66.46 \%$ (107/161) had poor knowledge, $31.68 \%(51 / 161)$ had moderate knowledge and 1.86\% (3/161) had good knowledge (Tables 2-4).

The distribution of answers to the knowledge questions are shown in Table 5 which showed that the vast majority of respondents knew that HBV can be contracted from a NSI, and that there is an effective vaccine to protect against HBV. However, it is also clear that the vast majority do not know just how effective the vaccine is or how long they will be protected against HBV after vaccination.

\section{Attitude of HCWS towards vaccination against HBV}

The second research objective in this study was to examine the attitudes of HCWs towards vaccination against HBV. There were seven statements to assess participants' attitude towards HBV. All the

Table 2. Distribution of knowledge of HCWs.

\begin{tabular}{|l|c|c|}
\hline \multicolumn{1}{|c|}{ Knowledge } & Frequency & Percent \\
\hline Poor knowledge & 107 & 66.46 \\
\hline Moderate knowledge & 51 & 31.68 \\
\hline Good knowledge & 3 & 1.86 \\
\hline Total & 161 & 100 \\
\hline
\end{tabular}

Table 3. Cross tabulation knowledge and being vaccinated.

\begin{tabular}{|l|c|c|c|}
\hline \multirow{2}{*}{ Knowledge } & Vaccination & Against HBV & Total \\
\cline { 2 - 4 } & No & Yes & \\
\hline Poor Knowledge's & 30 & 77 & 107 \\
\hline Moderate Knowledge's & 15 & 36 & 51 \\
\hline Good knowledge & 0 & 3 & 3 \\
\hline Total & 45 & 116 & 161 \\
\hline
\end{tabular}

Table 4. Frequency distribution of knowledge scores.

\begin{tabular}{|c|c|c|}
\hline Knowledge & Frequency & Percent \\
\hline 0 & 1 & .6 \\
\hline 1 & 17 & 10.6 \\
\hline 2 & 160 & 24.8 \\
\hline 3 & 49 & 30.4 \\
\hline 4 & 27 & 16.8 \\
\hline 5 & 14 & 8.7 \\
\hline 6 & 10 & 6.2 \\
\hline 7 & 2 & 1.2 \\
\hline 8 & 1 & .6 \\
\hline
\end{tabular}

Table 5. Distribution of answers to knowledge. statements had 5-point scale answers ranging from +2 (strongly agree) to -2 (strongly disagree) for positive statements, and from +2 (strongly agree) for negative statements. The distribution of answers to attitude question is shown in Table 6. Table 7 shows that the majority had a positive attitude among those who vaccinated, the majority $(82.8 \%)$, [176/116]) had a positive attitude towards vaccination as shown in Table 8 .

\section{Practices of HCWS regarding prevention of $\mathrm{HBV}$}

The third research objective in this study was to investigate the practice of HCWs regarding HBV prevention. The results for vaccination uptake and testing for immunity are presented in Table 9 , while Table 10 shows the distribution of vaccination uptake according profession, and Figure 1 illustrates the proportions of the vaccinated who had received between 1 and 3 doses of vaccine.

\section{Occupational exposures}

The majority of the HCWs (67.7\%, [109/161]) experienced needled stick injury. Among them, over a third (37.6\%, [41/81]) reported always and those who reported among them $40.7 \%$ (33/81) took PEP as show in Table 11. The chi-square test of association was used to find associations between vaccination uptake and demographic variables (Tables 12-14). Job category was the only variable that was significantly associated $\left(\mathrm{X}^{2}=4.563 ; \mathrm{P}=-0.049\right)$ with taking vaccination, and it was found that doctors were twice more likely to take the vaccinations as compared to nurses

\section{Discussion}

The main aim of the study is to investigate public awareness on hepatitis B virus among health workers. An overall response rate of $74.9 \%(161 / 215)$ was achieved in the study. This means that the results are adequately representative of the target population from which it was where the required $70 \%$ response.

Holbrook Allyson identifies response rates as a function of two different aspects of the interaction with respondents, namely contracting respondents and gaining their cooperation. There are different variables that have significance in non-response, namely, Occupation, income, number of hours worked, and knowledge of condition under survey.

Health care workers are at an increased risk of blood borne diseases. The most common form of accidental exposures is due to NSI. Exposures could also result from sharp objects such as scalpels and broken glasses, as well as from mucosal exposures after blood splash or bodily fluids [10]. A few questions on Knowledge were answered correctly by a majority of respondents. A majority of HCWs $(91.3 \%$ [147/161] knew that one could get HBV through a needle stick injury, and $87.6 \%(141 / 161)$ knew that there is an effective vaccine to protect

\begin{tabular}{|c|c|c|c|c|}
\hline \multirow[t]{2}{*}{$\mathbf{S} / \mathbf{N}$} & \multirow[t]{2}{*}{ Item statement } & True & False & Don't know \\
\hline & & No $(\%)$ & No $(\%)$ & No $(\%)$ \\
\hline 1. & Can get hepatitis B through a needle stick injury. & $147(91.3 \%)$ & $5(3.1 \%)$ & $9(5.6 \%)$ \\
\hline 2. & There is no effective vaccine for hepatitis B & $13(8.1 \%)$ & $141(87.6 \%)$ & $7(4.3 \%)$ \\
\hline 3. & There is no need for a blood test & $21(13 \%)$ & $117(72.7 \%)$ & $23(14.3 \%)$ \\
\hline 4. & Hepatitis B vaccine provides $100 \%$ protection for $90 \%$ adults. & $84(52.2 \%)$ & $37(23.0 \%)$ & $40(24.8 \%)$ \\
\hline 5. & Hepatitis B vaccine protects against HBV for at least 15 years & $49(30.4 \%)$ & $46(28.6 \%)$ & $66(41.0 \%)$ \\
\hline 6. & Vaccinated patients should not be considered as a possible source of HBV & $54(33.5 \%)$ & $82(50.9 \%)$ & $25(15.5 \%)$ \\
\hline 7. & A person vaccinated or recovered from hepatitis B infect others & $67(41.6 \%)$ & $65(40.4 \%)$ & $29(18.0 \%)$ \\
\hline 8. & HIV is more infections than hepatitis B virus. & $32(19.9 \%)$ & $109(67.7 \%)$ & $20(12.4 \%)$ \\
\hline 9. & For protection against hepatitis $B$, one needs a liter of at least $10 \mathrm{ml} / \mathrm{U} / \mathrm{ml}$ & $37(23.0 \%)$ & $23(14.3 \%)$ & $101(62.7 \%)$ \\
\hline
\end{tabular}


Table 6. Distribution of answers to attitudes questions.

\begin{tabular}{|c|c|c|c|c|c|}
\hline Hepatitis B Vaccination & Strongly agree & Agree & Do not know & Disagree & Strongly disagree \\
\hline Should be compulsory & $109(67.7 \%)$ & $39(24.2 \%)$ & $8(5 \%)$ & $4(2.5 \%)$ & $1(0.6 \%)$ \\
\hline Is too expenses & $8(5 \%)$ & $27(16.8 \%)$ & $84(52.2 \%)$ & $27(16.8 \%)$ & $15(9.3 \%)$ \\
\hline Scared of vaccination & $6(3.7 \%)$ & $14(8.7 \%)$ & $12(7.45 \%)$ & $65(40.5 \%)$ & $64(39.8 \%)$ \\
\hline Always careful therefore don't need it & $10(6.2 \%)$ & $26(16.11 \%)$ & $15(9.3 \%)$ & $73(45.6 \%)$ & $37(23.1 \%)$ \\
\hline Not at risk therefore don't need it & $3(1.9 \%)$ & $11(6.8 \%)$ & $19(11.8 \%)$ & $75(46.6 \%)$ & $53(32.9 \%)$ \\
\hline Don not trust & $4(25 \%)$ & $7(4.3 \%)$ & $12(7.5 \%)$ & $73(45.3 \%)$ & $65(40.4 \%)$ \\
\hline Against my religion/culture & $1(0.6 \%)$ & $4(25 \%)$ & $5(3.1 \%)$ & $63(39.1 \%)$ & $88(54.7 \%)$ \\
\hline
\end{tabular}

Table 7. Distribution of attitude of HCWs.

\begin{tabular}{|l|c|c|}
\hline \multicolumn{1}{|c|}{ Attitude } & Frequency & Percent \\
\hline Negative attitude & 1 & .62 \\
\hline Neutral & 40 & 24.84 \\
\hline Positive Attitude & 120 & 74.53 \\
\hline Total & 161 & 100 \\
\hline Source: Research Survey, 2011. & & \\
\hline
\end{tabular}

Table 8. Cross tabulation between attitude and being vaccinated.

\begin{tabular}{|l|c|c|}
\hline \multicolumn{1}{|c|}{ Attitude } & Vaccination & Against HBV \\
\hline & No & Yes \\
\hline Negatru attitude & 0 & 1 \\
\hline Neutral & 21 & 19 \\
\hline Positive attitude & 24 & 96 \\
\hline
\end{tabular}

Table 9: Distribution of answers to protection against hepatitis B.

\begin{tabular}{|c|c|}
\hline Vaccination and protection against hepatitis B & Number (2) \\
\hline Have you been vaccinated against hepatitis B virus (n=161) & $116(72.0)$ \\
\hline Yes & $39(24.2)$ \\
\hline Don't know & $6(3.7)$ \\
\hline Was your immunity against hepatitis B checked after vaccination? (n=116) \\
\hline Checked & $32(27.6)$ \\
\hline Not checked & $84(72.4)$ \\
\hline If checked, are you protected (n=32) & $30(93.75)$ \\
\hline Protected & $1(3.125 \%)$ \\
\hline Not protected & $1(3.125 \%)$ \\
\hline Don't know \\
\hline Source: Research Survey, 2011. \\
\hline
\end{tabular}

Table 10. Cross tabulation of being vaccinated against hepatitis B with job category.

\begin{tabular}{|c|c|c|}
\hline Job category & Vaccination & Against HBV \\
\hline & No or Do not know (\%) & Yes (\%) \\
\hline Doctor & $14(8.7)$ & $56(34.8)$ \\
\hline Nurse & $31(19.3)$ & $60(37.3)$ \\
\hline Total & $45(28)$ & $116(72)$ \\
\hline
\end{tabular}

against HBV. This is in contrast to studies done in Iran and the UK, where $21.4 \%$ and $44 \%$ respectively of HCWs knew that HBV can be transmitted by NSI $[11,12]$, and $38 \%$ of HCWs in Egypt not knowing how effective the vaccine is [13]. About two thirds (67.7\% [109/161]) of HCWs knew that HBV was more infectious then HIV. This was similar to a study done in Dublin, Ireland, where $82 \%$ of nurses knew that HBV transmission was 100 times more ineffective than HIV.

Finally, 50.9\% (82/161) knew that being vaccinated does not exclude on from being considered a possible source of hepatitis $B$, and $72.72(117 / 161)$ knew that one has to be tested in order to be sure that one is protected. This finding is similar to a study done in Dublin which showed that nurses had knowledge about the hepatitis B virus infection.
Table 11. Experience of needle stick injury among HCWs ( $n=161)$.

\begin{tabular}{|l|c|c|}
\hline No. of time needle stick injury & Frequency & Percent \\
\hline More than 10 times & 5 & 3.1 \\
\hline $6-10$ times & 17 & 10.6 \\
\hline $2-5$ times & 47 & 29.2 \\
\hline Once & 40 & 24.8 \\
\hline Never & 52 & 32.3 \\
\hline Injury reported (n=109) & & \\
\hline Never & & \\
\hline Sometimes & & \\
\hline Always & & \\
\hline PEP given (n=81) & 33 & 40.7 \\
\hline Yes & & \\
\hline No & & \\
\hline Source: Research Survey, 2011. & & \\
\hline
\end{tabular}

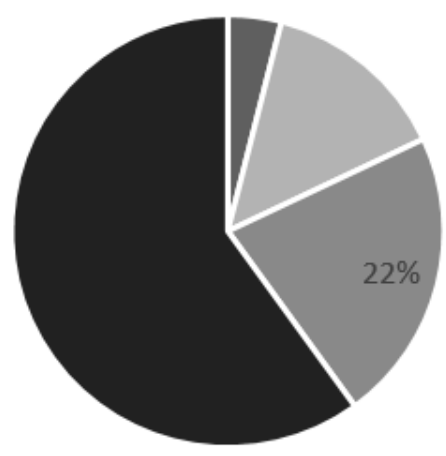

- Do not know $\quad 3$ doeses or more $\quad 2$ doses $\quad 1$ dose

Figure 1. Pie chart showing vaccine doses received.

This is demonstrated by the fact that of the $83 \%$ of HCWs who had completed a full course of hepatitis B Immunization, 93\% reported a hepatitis B antibody level on completion of the immunization; $14 \%$ knew their actual titer and 78\% reported immunity. Similarly, a study done in Birmingham, demonstrated that 70\% (153/218) HCWs stated that they treat every patient as if he is carrying a BBV.

What was disappointing is that a substantial number 23\% (37/161) of HCWs did not know for how long an individual could be protected against $\mathrm{HBV}$ after being vaccinated. This finding is similar to a study done in Egyptian HCWs, where it was found that $47 \%$ were not sure of how long they would be protected by the vaccine [13]. This study found that $66.5 \%(107 / 161)$ of HCWs had poor knowledge regarding vaccination against $\mathrm{HBV}$, with only $23 \%(107 / 161)$ knowing that one 
Table 12. Cross tabulation of gender and vaccination against HBV.

\begin{tabular}{|l|c|c|c|}
\hline Gender & Vaccination & Against HBV & Chi-square test \\
\hline & Yes & No & \\
\hline Male & 34 & 12 & $0.065(\mathrm{P}=0.847)$ \\
\hline Female & 84 & 32 & \\
\hline
\end{tabular}

Table 13. Cross tabulation of job category and vaccination against HBV.

\begin{tabular}{|l|c|c|c|}
\hline Job category & Vaccination & Against HBV & Chi-square test \\
\hline & Yes & No & \\
\hline Doctor & 56 & 13 & $4.563(\mathrm{P}=0.049)$ \\
\hline Nurse & 60 & 31 & \\
\hline
\end{tabular}

Table 14. Cross tabulation of duration as HCW and vaccination against hepatitis B virus.

\begin{tabular}{|l|c|c|c|}
\hline Duration as HCW & Vaccination & Against HBV & Chi square test \\
\hline & Yes & No & \\
\hline 5 years or less & 34 & 10 & \\
\hline $6-10$ years & 17 & 7 & \\
\hline $11-15$ years & 17 & 6 & $2.998(\mathrm{P}=0558)$ \\
\hline $16-20$ years & 20 & 5 & \\
\hline More than 20 years & 28 & 16 & \\
\hline
\end{tabular}

needs a titre of at least $10 \mathrm{M} / \mathrm{U} / \mathrm{M}$ of antiHBs in order to be protected against HBV. This raises the suspicion that HCWs have not been adequately trained aboutBBVs. The study done is similar to a study done in Egypt which demonstrated that $47 \%$ of HCWs did not exactly know the duration of vaccine validity [13].

This study found that $55.9 \%(90 / 161)$ had a positive attitude towards $\mathrm{HBV}$ vaccination, which is similar to a study done in Birmingham where more nurses $(86 \%)$ than doctors $(41 \%)$ had the attitude that all patients should be treated as if they have a blood-borne virus. The majority of HCWs (91.3\%) knew that one can get HBV through a NSI, and the majority $79.5 \%(128 / 161)$ of HCWs did perceive themselves to be at risk of exposure to HBV since they either disagreed or strongly disagreed that they were "not at-risk for hepatitis because I am always careful when examining patients and taking specimens". This finding is similar to a study done in Iran which showed that $70 \%$ of HCWs were concerned about BBV, but despite this, their use of protective material appeared to be influenced by the perceived risk of transmission [11].

The majority of HCWs $67.7 \%$ (109/161) and 24.2\% (39/161), either strongly agreed or agreed respectively, that hepatitis vaccination should be made compulsory. In addition, 68.3\% (119/161) of HCWs either did not agree or did not strongly agree that "being careful" qualified one for "not being at risk for HBV" when examining patients and taking specimens. This finding is similar to those of a study done in Texas, where only $8 \%$ of participating nurses were not willing to be vaccinated against Hepatitis B, since they perceived themselves to be at low risk as they were practicing as nurses and there was lack of concern about getting the illness.

Only $22.4 \%$ (36/161) HCWs agreed that they were not at risk for HBV because of always being careful when examining patients and taking specimens. A majority $85.7 \%$ (138/161) of HCW s either disagreed or strongly disagreed on a question 'I do not trust vaccinations', and 93.7\% (151/161) either disagreed or strongly disagreed on vaccination is against my religion/traditional beliefs.

In contrast to studies done in Sweden [14] and Nigeria [15] where HCWs had a negative attitude towards vaccination because it was expensive, the majority (52.2\%) [84/161]) of HCWs in this study did not know that it is expensive, and therefore did not have a negative attitude towards it's expense. This finding may be due to the HCWs not having to pay for the vaccine themselves, but the question about who pays for their vaccination was not posed to the participants.

The majority of HCWs (72\%) [116/161]) has been vaccinated against HBV, however of those vaccinated, only $27.6 \%(32 / 116)$ had their immunity checked and $93.75 \%$ (30/31) stated they were protected. This is in contrast to a study done in Kenya where it was found that only $12.82(71 / 554)$ of HCWs had received vaccination previously and none had been screened for immunity or HBsAg [8]. In this study, $91.3 \%$ of HCWs knew that HBV was transmitted through a NSI but despite this, only $55.92 \%$ of them always were protective clothing when handling blood or body fluids and 38.5 said occasionally. These findings compare favorably to the practice of HCWs seen in Iran, where only $27 \%$ said they wore gloves all the time and 69\% said occasionally [11].

Nevertheless, injuries go undocumented in many developing countries as compared to the US, where one out of three needle stick injuries and reported. It has been pointed out that the prevention of an occupational infection with BBVs like HBV is dependent on the integration of exposure avoidance, immunization, and PEP. Overall, it was found that $71.2 \%$ had scored 12 or more indicating overall practices towards HBV prevention was good. Nurses had a higher mean score $(\mathrm{m}=13.09)$ for practice compared to doctors $(\mathrm{m}=12.11)$ and the difference was statistically significant $(t=2.14, p=0.17)$. This finding is similar to a study done in Birmingham where it was found that only $2 \%$ of the nurses did not report a NSI as compared to $28 \%$ of doctors who did not, which was statistically significant [12].

Although knowledge about vaccination for HBV was found to be generally poor, fortunately poor knowledge was not found to be a statistically significant barrier to vaccination, nor was good knowledge found to be a statistically significant predictor of vaccination uptake. This finding is similar to a study done in Houston, USA where vaccine effectiveness and the belief that they were at risk of exposure were cited as reason for being vaccinated by registered nurses.

However, a study done in Nigeria demonstrated that workers thought to have greater knowledge about HBV infection (doctors and nurses) were the ones who were less interested in receiving the vaccine. Non-clinical workers (medical record personnel (76/3\%) and engineering staff $(69.5 \%)$ demonstrated greater compliance, whilst clinical professional nurses (39.7\%) and doctors (40.3\%) showed less compliance [9].

Finally, it was found that being a doctor was statistically significantly associated with vaccination uptake, with doctors being 2.23 times more likely to be vaccinated than nurse $(\mathrm{P}=0.049)$. This finding stands in contrast to a study done in Saudi Arabia which demonstrated an overall compliance to hepatitis B vaccination of 78.7\% (37/47) amongst all categories of Hews in ICU.

\section{Conclusion}

It can be concluded from the study that there was overall lack of knowledge amongst the majority of HCWs, despite a positive attitude in the majority of them. This positive attitude was found to be a predictor of vaccination uptake and fortunately poor knowledge was not found to be a barrier. Nevertheless, it is that training in BBVs is suboptimal at the tertiary institutions that train these HCWs.

There is a lack of implementation of policies shown in this study as reflected by the following: inadequate safe injection practices observed as more than fifty percent of HCWs experienced needle stick injuries; 
protective clothing was not worn by HCWs such as the HCWs right to protection against $\mathrm{BBV}$ is contravened. Not all HCWs were vaccinated, not all those vaccinated were given 3 doses, and not all those vaccinated were tested for immunity. It is thus, clear that there is no consistent vaccination policy at the institutions where these HCWs were employed. There is an existing gap at Nigeria health care facilities in the management of hepatitis B virus amongst HCWs, despite the vaccinate being approved by the National Department of Health (NDH).

\section{Recommendations}

There is a need to inform the HCWs of the availability of an effective, safe vaccine that prevents HBV. This has been identified as a cost-effective public health intervention for protection against HBV. Although a majority of HCWs demonstrated a positive attitude, education on HBV infection has to be continued to target those who still have a negative attitude and to prevent regression.

All health care facilities should have programs designed to minimize risk, including infection control programs. This demonstrate the fact that it is both the duty of the employee and the employer to curtail the spread of the infection.

It is recommended that hepatitis B vaccine protocol should available at each health care facility, and a representing body to monitor and evaluate policies that are in place, and to see to it that they are implemented and adhered to.

In addition, programs need to be implemented to identify HBsAg Positive HCWs and to refer them for appropriate medical management, and provide vaccination to their contacts, preferable, this should be done at the beginning of the HCWs profession. Extending these services to HCWs identified as HBsAg positive with help preventing squeal in chronically infected HCWs and enhances vaccination strategies for elimination of HBV transmission.

\section{References}

1. Idraes M, Khans S, Riazuddin S (2004) Common genotype of hepatitis B virus. J Coll Phy Surv Pak 14: 244-247.
2. Ali L, Idraes M, Ali M, Rehman I, Hussain A, et al. (2011) An overview of treatment response rates to various antiviral drugs in Pakistani Hepatitis B virus infected patient. Virology J 8: 20.

3. Li G, Li W, Guo F, Xu S, Zhao N, et al. (2010) A novel real-time PCR assay for determination of viral loads in person infected with hepatitis B virus. $J$ Virol Methods 165: 9-14. [Crossref]

4. Alam MM, Zaidi SZ, Malik SA, Naeem A, Shaukat S, et al. (2007) Serology based disease status of Pakistani population infected with hepatitis B virus. BMC Infect Dis 7: 64. [Crossref]

5. Davis LG, Weber DJ, Lemon SM (1989) Horizontal transmission of hepatitis B virus. Lancet 1: 889-893. [Crossref]

6. Hollinger FB, Liang TJ (2001) Hepatitis B Virus. In: Fields Virology. ( $4^{\text {th }}$ edn.), Lippincott Williams and Wilkins, Philadelphia pp: 2971-3036.

7. Kermode M, Jolley D, Langkham B, Thomas MS, Crofts N (2005) Occupational exposure to blood and risk of bloodborne virus infection among health care workers in rural north Indian health care settings. Am J Infect Control 33: 34-41. [Crossref]

8. Suckling RM, Taegtmeyer M, Nguku PM, Al-Abri SS, Kibaru J, et al. (2006) Susceptibility of healthcare workers in Kenya to hepatitis B: new strategies for facilitating vaccination uptake. J Hosp Infect 64: 271-277. [Crossref]

9. Fatusi AO, Fatusi OA, Esimai AO, Onayade AA, Ojo OS (2000) Acceptance of hepatitis B vaccine by workers in a Nigerian teaching hospital. East Afr Med J 77: 608-612. [Crossref]

10. De Villiers HC, Nel M, Prinsloo EAM (2007) Occupational exposure to bloodborne viruses amongst medical practitioners in Bloemfontein, South Africa. SA Fam Pract 49: 14

11. Moghimi M, Marashi SA, Kabir A, Taghipour HR, Faghihi-Kashani AH, et al. (2007) Knowledge, Attitude, and Practice of Surgeons about Blood-Borne Diseases. J Sur Research 22: 4804-4808. [Crossref]

12. Stein AD, Makarawo TP, Ahmad MFR (2003) A survey of doctors' and nurses' knowledge, attitudes and compliance with infection control guidelines in Birmingham teaching hospitals. J Hosp Infect 54: 68-73. [Crossref]

13. EI-Awady MY (1998) Hepatitis B vaccination among medical personnel at Ain Shams University Hospital and obstacles to vaccine uptake. J Egypt Public Assoc 73: 519-537. [Crossref]

14. Dannetun E, Tegnell A, Torner A, Giesecke J (2006) Coverage of hepatitis B vaccination in Swedish healthcare workers. J Hosp Infect 63: 201-204. [Crossref]

15. Adebamowo CA, Ajuwon A (1997) The immunization status and level of knowledge about hepatitis B virus infection among Nigerian surgeons. West Afr J Med 16: 93-96. [Crossref]

Copyright: (C2016 Ekpenyong MS. This is an open-access article distributed under the terms of the Creative Commons Attribution License, which permits unrestricted use, distribution, and reproduction in any medium, provided the original author and source are credited. 